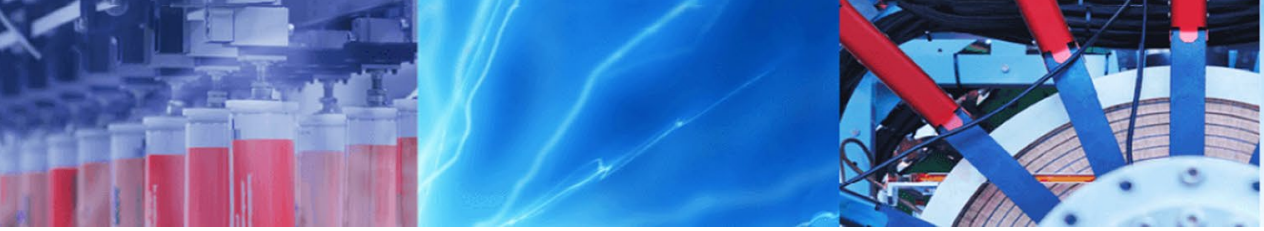

Research Article

\title{
Study on incorporating wattle tannin in polyvinyl acetate emulsion and its effect on properties for wood bonding application
}

\author{
Rajesh Prabhu' ${ }^{1} \cdot$ Ramanand Jagtap ${ }^{1} \cdot$ Mohanlal Digar $^{2}$
}

Received: 7 April 2020 / Accepted: 15 September 2020 / Published online: 23 September 2020

(c) Springer Nature Switzerland AG 2020

\begin{abstract}
Polyvinyl acetate emulsion (PVAc) is an essential class of adhesives for woodworking applications. However, it suffers from low water resistance. In the present research, wattle tannin was incorporated in synthesised PVAc emulsion at ratios ranging from 0 to $6 \mathrm{wt} . \%$ in PVAc emulsion. The study was carried out in two parts. The first part focuses on understanding the effect of the presence of tannin in PVAc emulsion on its adhesive performance. The second part deals with the study of the variation in adhesive properties of tannin PVAc emulsion adhesive by introducing isocyanate crosslinker in the system. DMA was employed to understand the glass transition and rheology behaviour. FTIR was used to assess the reaction of tannin with isocyanate crosslinker. Contact angle measurement was measured using goniometry to understand the surface wettability achieved by incorporating tannin in the PVAc emulsion system. Detail study on adhesive strength was carried out by bonding wood substrates followed by measuring bonding strength in wet conditions as per BS EN 204 and heat resistance as per DIN EN 14257 (WATT 91). The presence of tannin in the system enhances water and heat resistance property which gets further improved in the presence of isocyanate crosslinkers. The observed effect is due to better wetting of substrate by adhesive, hydrogen bonding between tannin and components in adhesive, and dense crosslinking formed by the reaction of isocyanate crosslinker.
\end{abstract}

Keywords Tannin · Polyvinyl acetate $\cdot$ Adhesive $\cdot$ Water resistance $\cdot$ Crosslinking $\cdot$ Emulsion $\cdot$ Wood adhesive $\cdot$ Heat resistance

\section{Introduction}

Tannin is a natural water-soluble polyphenolic compound ranging from the molecular mass of 300-3000 $\mathrm{Da}$ [1] found abundant in plants $[2,3]$. Tannin is present in superior plants such as mimosa, chestnut and oak to protect lingocellulosic material against biological and radiative degradation due to their chemistry and antioxidant property [4-6]. Tannin is commercially essential due to its usefulness in pharmaceutical, food and nutrients-based applications. [7]. Mimosa, quebracho and pine tannins find use in commercial purposes due to their availability. The industrial grade of tannin available contains a significant portion as tannin, while sugar and hydrocolloid gum form the nontannin part $[2,8]$. The hydroxyl group of tannin reacts with the isocyanate group [9] and has different reactivity. The viscosity change of the two-component adhesive system with time shows the reaction rate and molecular growth of the polymeric chain. Wattle tannin (resorcinol), when reacted with paraformaldehyde, has a gel time of 950 (s) as compared to pine tannin extract (phloroglucinol) which has a gel time of 65 (s) [10] which makes wattle tannin a preferred choice for adhesive due to long open time, availability and its similarity with resorcinol. $[7,11]$

The techniques of bonding materials using adhesives are popular since ages. However, the use of adhesive in

Rajesh Prabhu, rajeshprabhu1989@gmail.com | 'Department of Polymer and Surface Engineering, Institute of Chemical Technology, Mumbai 400019, India. ${ }^{2}$ Research and Development, Pidilite Industries Limited, Mumbai 400059, India. 
furniture and wood bonding applications became popular from the last century. At present, adhesive systems for bonding wood for external use include urea-formaldehyde (UF), phenol-formaldehyde (PF) and one component polyurethane resin (1 K PUR). The main drive for today's increasing interest in bio or renewable adhesives is due to environmental protection and health-related concerns about formaldehyde emissions $[2,3,7,8,11,12]$ and fluctuation in petroleum prices. $[2,3,11,12]$. Tanninbased adhesives have already been used for particleboard preparations commercially $[8,13]$. Though phenol-formaldehyde and melamine formaldehyde-based adhesives exhibit superior heat and water resistance properties, they have the inherent tendency of formaldehyde emission with time $[2,7,12]$. Polyurethane adhesives are equally good or even superior to PF and UF adhesives in terms of heat and water resistance properties; however, they are expensive and difficult to handle due to its hazard to human health.

Researchers have been working on the improvement of tannin-based adhesives using various routes. Kim [12] have reported a decrease in formaldehyde emission in flooring adhesive by blending PVAc adhesive with tannin paraformaldehyde adhesive. Rhazi et al. [2] have reported the commercial equivalent of Phenol formaldehyde for plywood bonding prepared by tannin lignosulfonate adhesives along with hexamine. Tondi [6] studied the effect of various crosslinkers viz. formaldehyde, hexamine, glyoxal, maleic anhydride, furfural and furfuryl alcohol when crosslinked with tannin at different $\mathrm{pH}$ and temperature conditions. Garhi et al. [7] prepared complete green adhesive of soy and tannin for plywood applications. Sowunmi et al. [3] modified mangrove tannin with anhydride and PF blend to obtain commercial PF equivalent adhesive for plywood applications. Elbadawi et al. [13] added tannin to UF adhesives to decrease cost and improve properties of particle boards. Kim et al. [14] studied different combinations of tannin paraformaldehyde hexamine and pMDI for preparation of particle board to keep the performance equivalent to commercial UF resins.

Polyvinyl acetate emulsion (PVAc) adhesive is a popular class of non-hazardous adhesive for wood bonding application. PVAc adhesives are synthesised via emulsion polymerisation technique stabilised by colloids (polyvinyl alcohol) and surfactants [15]. The popularity of PVAc adhesive is due to its non-hazardous nature, easy application and low cost. However, PVAc chemistry shows poor water resistance, thermal stability and dimensional stability. Emulsion polymer isocyanates (EPI) are a popular class of adhesives where emulsions particularly PVAc emulsions are blended with isocyanates-based crosslinkers to improve mechanical properties and water resistance. [16, 17]

\section{SN Applied Sciences}

Recent studies show the improvement of water resistance and heat resistance properties of PVAc adhesive in several ways. Adamopoulos et al. [18] reported that the water resistance, as well as mechanical properties of PVAC adhesive, can be improved by treating beech wood samples with phenol-formaldehyde before applying adhesives. Gua et al. [16] have studied the effect of blending isocyanatebased polymeric MDI crosslinker in an emulsion. They found that mechanical properties of emulsion film improve on crosslinking it with isocyanate-based crosslinker. Khan et al. [19] studies show improvement of adhesive strength and toughness of PVAC adhesive by adding graphene into the system. Fang et al. [15] report improving mechanical properties of PVAC-co-NMA adhesive by incorporating exfoliated MMT. Brown and Frazier [20] show property variation in PVAC-co-NMA self-crosslink system by altering the sequence of NMA addition. Few commercial adhesives include copolymerisation products of vinyl acetate and crosslinking agents such as $\mathrm{N}$ methylol acrylamide. NMA crosslinks with the other NMA groups and the hydroxyl group of $\mathrm{PVOH}$ at lower $\mathrm{pH}$ conditions which produce formaldehyde as a by-product. The crosslinking improves the crosslinking density, which improves water resistance. [20, 21]. Hass et al. [22] have studied the effect of various physical parameters on the bonding of PVAc adhesive in wood bonding application. Lu et al. [23] have attempted to improve water resistance by incorporating VEVOA 10 and AAEM [acetoxy ethyl methacrylate] in PVAc system followed by crosslinking the copolymer with a diamine. Much research has been carried out for twocomponent PVAc adhesive crosslinked with isocyanates [17]

BS EN 204 standards [24, 25] governs and specifies wood bonding strength values. Table 1 mentions the criterion for conditioning the substrates and minimum values of adhesive bonding strength required for qualifying durability classes.

In our current research, we focus on studying the effect of incorporating wattle tannin in PVAc emulsion adhesive on its water resistance and heat resistance properties. Further, we aim to crosslink tannin PVAc emulsion adhesive with isocyanate-based crosslinker to prepare the EPI system. Due to polyphenolic and multi-hydroxyl nature of tannin, we believe tannin will act as collide, and due to the interaction of tannin with components of adhesive water resistance and heat resistance property will improve. Hydroxy group of tannin will further help in creating dense crosslinking when cured with the crosslinker. 
Table 1 Conditioning of wood substrates bonded with adhesive and bonding strength required for qualifying durability classes as per EN 204

\begin{tabular}{|c|c|c|c|c|c|}
\hline \multicolumn{2}{|c|}{ Conditioning sequences } & \multirow{2}{*}{\multicolumn{4}{|c|}{$\begin{array}{l}\text { Bonding strength in N/ } \\
\mathrm{mm}^{2}\end{array}$}} \\
\hline \multirow[b]{2}{*}{ Sr. no } & \multirow[b]{2}{*}{ Duration and condition } & & & & \\
\hline & & $D 1$ & $D 2$ & D3 & $D 4$ \\
\hline 1 & 7 Days in standard atmosphere* & $\geq 10$ & $\geq 10$ & $\geq 10$ & $\geq 10$ \\
\hline \multirow[t]{3}{*}{2} & 7 Days in standard atmosphere & & $\geq 8$ & & \\
\hline & $3 \mathrm{~h}$ in water at $(20 \pm 5)^{\circ} \mathrm{C}$ & & & & \\
\hline & 7 Days in a standard atmosphere & & & & \\
\hline \multirow[t]{2}{*}{3} & 7 Days in a standard atmosphere & & & $\geq 2$ & $\geq 4$ \\
\hline & 4 Days in water at $(20 \pm 5)^{\circ} \mathrm{C}$ & & & & \\
\hline \multirow[t]{3}{*}{4} & 7 Days in a standard atmosphere & & & $\geq 8$ & \\
\hline & 4 Days in water at $(20 \pm 5)^{\circ} \mathrm{C}$ & & & & \\
\hline & 7 Days in a standard atmosphere & & & & \\
\hline \multirow[t]{3}{*}{5} & 7 Days in a standard atmosphere & & & & $\geq 4$ \\
\hline & $6 \mathrm{~h}$ in boiling water & & & & \\
\hline & $2 \mathrm{~h}$ in water at $(20 \pm 5){ }^{\circ} \mathrm{C}$ & & & & \\
\hline
\end{tabular}

*Standard atmosphere condition $(20 \pm 2){ }^{\circ} \mathrm{C}$ and $(65 \pm 5) \%$ relative humidity or $(23 \pm 2)^{\circ} \mathrm{C}$ and $(50 \pm 5) \%$ relative humidity

\section{Experimental}

\subsection{Materials}

\subsubsection{Emulsion preparation}

Vinyl acetate monomer (VAM) was kindly donated by Pidilite Industries Limited, India. Partially saponified polyvinyl alcohol (PVOH) with a saponification value of $88 \%$ was obtained from Kuraray, Japan. Laboratory grade of potassium persulfate and sodium bicarbonate were purchased from Merck. All the chemicals mentioned were used as received without purification.

\subsubsection{Formulation}

Wattle tannin powder was supplied by Sriguru chemicals [\% VOC 6-7\%, Tannin content $=75 \%$ ], India. Isocyanatebased crosslinker used was Bayhydur 304 [\% NCO = 18.3\%, viscosity at $25 \pm 2{ }^{\circ} \mathrm{C}=5000 \mathrm{cps}$ ] procured from Covestro, Germany. Bayhydur 304 is hydrophobically modified aliphatic isocyanate based on HDI. Henceforth in the current paper, we shall mention tannin for wattle tannin powder and crosslinker for Bayhydur 304.
Table 2 List of ingredients for synthesising polyvinyl acetate emulsion

\begin{tabular}{lc}
\hline Ingredients & Quantity (g) \\
\hline PVOH & 205.00 \\
Deionised water & 1845.00 \\
Vinyl acetate monomer & 2380.00 \\
Potassium persulphate, initiator & 8.75 \\
Deionised water & 210.00 \\
Sodium bisulphate, buffer & 7.50 \\
Deionised water & 343.75 \\
Total & 5000.00 \\
\hline
\end{tabular}

\subsection{Methods}

\subsubsection{Adhesive synthesis}

The emulsion synthesis process was utilised to synthesise the PVAc emulsion adhesive. Recipe for the synthesis of PVAc emulsion is mentioned in Table 2. The adhesive was prepared in a 5-litre glass kettle attached with a lid having five inlets immersed in a water bath with a temperature control system. The kettle was equipped with a dropping funnel, reflux condenser and an anchorshaped stirrer.

2.2.1.1 Pre-polymerisation preparation The calculated amount of deionised water and $\mathrm{PVOH}$ were taken in the kettle and stirred at $100 \mathrm{rpm}$ for $2 \mathrm{~h}$ and at $90^{\circ} \mathrm{C}$ to form a $10 \%$ non-VOC solution. A $4 \%$ non-VOC solution of potassium persulphate was prepared using deionised water. The solution was divided into three parts which consist of part A, part B and part C. Twenty per cent of solution was part $A$, belonging to pre-catalyst. Part B was $60 \%$ of the catalyst solution utilised during polymerisation. Remaining $20 \%$ of catalyst solution belongs to part C, used as a post catalyst. A jar with a measured quantity of VAM was attached to reaction kettle via a peristaltic pump. Peristaltic pump facilitates controlled addition of VAM during polymerisation.

2.2.1.2 PVAc polymerisation The collide solution prepared was cooled to $80{ }^{\circ} \mathrm{C}$, and sodium bisulphate was added as a buffer along with deionised water. Part A of catalyst solution was added to the kettle under stirring, and part $B$ was loaded in dropping funnel. VAM and part B of catalyst solution were added dropwise for a period of $5 \mathrm{~h}$. The reaction temperature was set between 80 and $84{ }^{\circ} \mathrm{C}$ and stirring was maintained between 120 and $140 \mathrm{rpm}$. After $5 \mathrm{~h}$, Part $\mathrm{C}$ of the catalyst solution was added in the emulsion and stirred for $1 \mathrm{~h}$ at $85^{\circ} \mathrm{C}$. The targeted non-VOC of PVAc emulsion was 52\%. 


\subsubsection{Formulation}

Aqueous tannin solution of $40 \%$ non-VOC (weight basis) was prepared in deionised water. The adhesive solution was prepared at room temperature under stirring until the homogenous mixture was obtained. (2) The calculated amount of tannin solution was blended slowly with PVAC emulsion. Tannin solution was added dropwise to avoid any lumps and grits formation. Mixing time of 20 min was set for each sample, assuring uniform mixing by visual observation. (3) Tannin PVAc emulsion adhesive was aimed at $46 \%$ non-VOC content, and it was obtained by adjusting the non-VOC content of the blend with deionised water.

For studying the crosslinking effect, prepared tannin PVAc emulsion adhesives were further blended with different proportions of crosslinker to develop an EPI. Mechanical stirring was employed for blend preparation. Table 3 explains in detail about the variation of tannin concentration in tannin PVAc emulsion adhesive, the variation of crosslinker across the blends and nomenclature for each adhesive blend. We will follow for further discussions in this research article. For example, a sample with name PA 4/2.5 indicates $4 \%(\mathrm{w} / \mathrm{w})$ of dry tannin added to $100 \mathrm{~g}$ [non-VOC part of PVAc emulsion] and made it to $46 \%$ nonVOC tannin PVAc emulsion adhesive. The prepared blend was mixed with 2.5 parts of crosslinker per 100 parts of tannin PVAc emulsion adhesive.

\subsubsection{Tannin PVOH miscibility study}

Tannin and PVOH are hydrophilic in nature, and they form hydrogen bonds when mixed. For understanding the extend of miscibility of tannin with PVOH present in the emulsion, a separate experiment was performed. In the experiment, $10 \%$ non-VOC solutions of $\mathrm{PVOH}$ and tannin were prepared in deionised water, respectively. In a kettle, individually prepared solutions of tannin and PVOH were mixed in different ratios to form a solution of tannin/PVOH

Table 3 Details on tannin and crosslinker concentration in adhesive blends

\begin{tabular}{llll}
\hline $\begin{array}{l}\text { Tannin concentration } \\
(\%)\end{array}$ & \multicolumn{3}{l}{ Crosslinker quantity $^{\mathrm{b}}(\mathrm{pph})$} \\
\cline { 2 - 4 } & 0 & 2.5 & 5 \\
\hline 0 & PA $0 / 0.0$ & PA $0 / 2.5$ & PA $0 / 5.0$ \\
1 & PA $1 / 0.0$ & PA $1 / 2.5$ & PA $1 / 5.0$ \\
2 & PA 2/0.0 & PA 2/2.5 & PA 2/5.0 \\
4 & PA 4/0.0 & PA 4/2.5 & PA 4/5.0 \\
6 & PA 6/0.0 & PA 6/2.5 & PA 6/5.0
\end{tabular}

${ }^{\mathrm{a} C o n c e n t r a t i o n}$ of tannin is calculated based on the dry weight of tannin to dry weight [non-VOC content] of prepared PVAc emulsion

${ }^{b}$ Crosslinker per 100 parts of tannin PVAc emulsion adhesive blend. Ratios of tannin/PVOH selected were 0/100, 5/95, 10/90, 15/85, 20/80, 25/75.

\subsubsection{Viscosity}

The reaction between crosslinker and components of PVAC emulsion adhesive leads to rises the viscosity of the system with time. Viscosity variation was studied for PA 0/5.0 and PA 4/5.0. $400 \mathrm{~g}$ of PA $0 / 0.0$ and PA 4/0.0 were measured in the respective containers, and 5 parts per hundred resin (pph) of crosslinker were added to each container. The outcome of the mixing was PA 0/5.0 and PA 4/5.0. Viscosity was measured at a regular time interval. The containers were closed with an aluminium foil to avoid loss of water. The change in viscosity was measured at $30^{\circ} \mathrm{C}$ using a Brookfield RVT model with spindle no 6 or 7 at $20 \mathrm{rpm}$ speed for the duration of $24 \mathrm{~h}$ from the time of adding the crosslinker. The rise in viscosity rise was reported as a per cent change in viscosity concerning initial viscosity.

\subsubsection{Fourier transform infrared spectroscopy (FTIR)}

FTIR is suitable for studying the interaction between the chemical groups. FTIR spectroscopy predicts the reaction of the crosslinker with the blend. Fifteen gram of aqueous tannin solution ( $40 \%$ weight basis) was mixed with $1 \mathrm{~g}$ crosslinker, and the mixture was allowed to react for 7 days at room temperature. The reaction provides a hard material on curing, which was washed with deionised water twice and dried in an oven at $105^{\circ} \mathrm{C}$ for $4 \mathrm{~h}$. FTIR spectrum was recorded on PerkinElmer FTIR spectrophotometer of spectrum 100 assisted by diamond ATR.

\subsubsection{Dynamic mechanical analysis (DMA)}

DMA is an accurate way of determining glass transition temperature $\left(T_{g}\right)$. Following are three ways to determine $T_{\mathrm{g}}$ from DMA analysis: (a) The peak of the tan delta curve denotes $T_{\mathrm{g}}$ ( (b) The peak of loss modulus curve indicates the onset of segmental motion and $T_{\mathrm{g}}$; (c) From slope intersection of storage modulus curve [26]. We aim to compare the change in $T_{g}$ for tannin PVAc blends, and hence, we refer peak of tan delta curve for $T_{\mathrm{g}}$ calculation. Since tan delta value is the ratio of loss modulus to storage modulus, dimensional stability factor in the calculation of $T_{\mathrm{g}}$ is eliminated. PA 0/0.0, PA 2/0.0, PA 4/0.0 and their respective EPI prepared by adding 2.5 and 5 pph of crosslinker were tested for DMA analysis. Films of the samples were cast on a silicon paper and dried for 7 days before testing at $25 \pm 2{ }^{\circ} \mathrm{C}$ and $65 \pm 5 \%$ of relative humidity (RH). The casting was done with a film applicator of $200 \mu \mathrm{m}$ coating thickness to obtain dry film thickness was between 80 and $100 \mu \mathrm{m}$. DMA analysis was carried using a TA Instruments 
Q800 dynamic mechanical analyser (USA) in a film-tension geometry mode at a frequency of $1 \mathrm{~Hz}$. The temperature ranged from -30 to $150^{\circ} \mathrm{C}$ at a heating ramp rate of $5^{\circ} \mathrm{C} /$ $\min$

\subsubsection{Goniometry}

The water contact angle was measured to understand the effect of tannin on surface wetting properties of PVAc tannin blend. Tannin PVAc emulsion adhesives were coated on a glass plate using 200-micron applicator. Films were dried for 7 days at $25 \pm 2{ }^{\circ} \mathrm{C}$ and $65 \pm 5 \% \mathrm{RH}$. Five measurements for each sample were taken. The droplet size was kept constant at $10 \mu \mathrm{L}$. The test was carried on the RameHart Goniometer instrument.

\subsubsection{Bonding strength}

Tannin PVAc adhesive was applied on a step-cut unsteam beech wood substrates with a bonding area of $(2 \times 2)$ sq. $\mathrm{cm}$ followed by applying static pressure of $1 \mathrm{MPa}$. The adhesive was applied on the substrates at $25 \pm 2{ }^{\circ} \mathrm{C}$ and $65 \pm 5 \% \mathrm{RH}$, followed by the conditioning of the substrates for 7 days at the same temperature and humidity condition. After 7 days, samples were released from the clamps and were conditioned again at $25 \pm 2{ }^{\circ} \mathrm{C}$ and $65 \pm 5 \% \mathrm{RH}$ for 7 days. The substrates were conditioned as per BS EN 204, D1, D2, D3 [24] and DIN 14257/WATT 91 [27], respectively. Henceforth, in this research article, bonding strength for the substrates conditioned as per BS EN 204/D1 termed as $D 1$ bonding strength and similarly for substrate conditioned as per BS EN 204/D2, D3 and DIN 14257/WATT91 will be termed as D2 bonding strength, D3 bonding strength and heat resistance bonding strength, respectively. For each test, at least five samples were prepared, and standard deviations were calculated. Bond strength evaluation was carried on a universal testing machine (UTM) of making Amil technologies. Load cell capacity of UTM was $25 \mathrm{KN}$, and crosshead speed was $5 \mathrm{~mm} / \mathrm{min}$. Figure 1 shows the side view and top view of the bonded substrate.

\section{Results and discussion}

The synthesised polyvinyl acetate emulsion has a milky white appearance, viscosity of 598 poise, non-volatile content of $51.60 \%$ and $\mathrm{pH}$ of 4.52 . The prepared emulsion was used for further formulations with tannin and crosslinker.

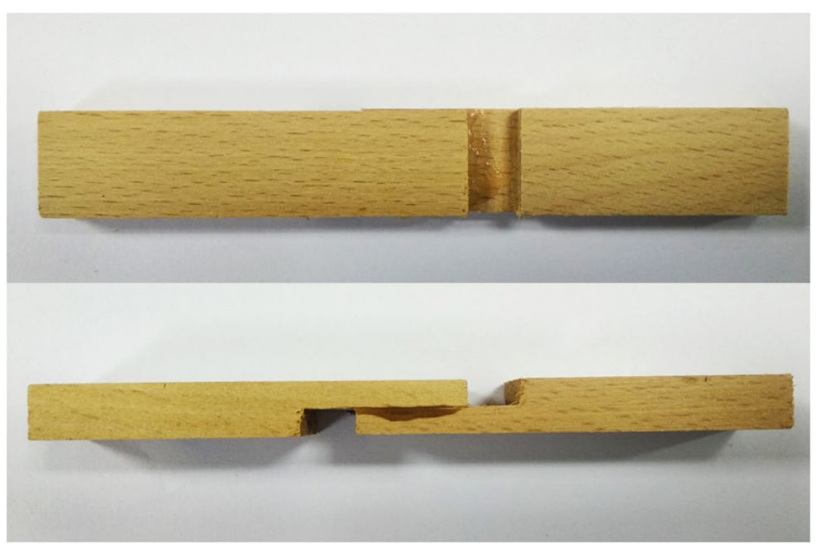

Fig. 1 Top view and side view of beech wood substrates bonded using PA4/5.0

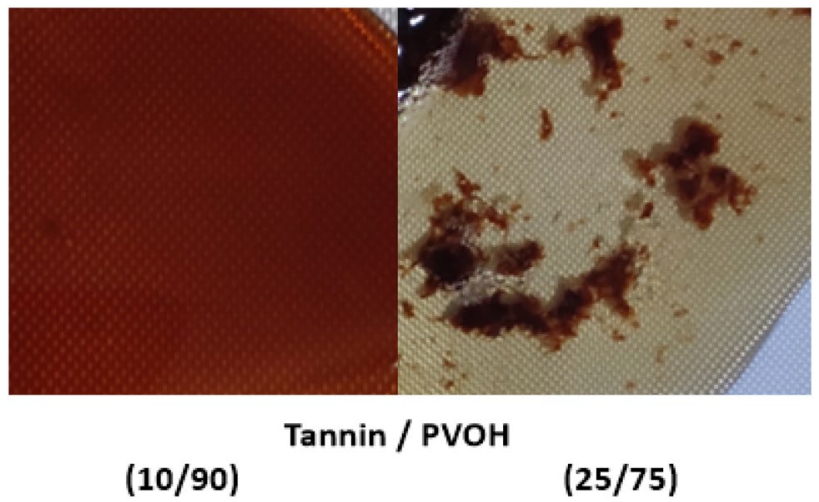

Fig. 2 Image of wet films of tannin/PVOH cast for understanding homogeneity in the blend

From the tannin PVOH blend, we observed a smooth homogenous solution until the tannin/PVOH ratio was $15 / 85$. At the ratio of $20 / 80$, gelling was observed, and at the ratio of $25 / 75$, coagulation was observed in the blend. The observation is attributed to the formation of dense hydrogen bonding which helps tannin and polyvinyl alcohol to bind tightly and forms coagulation in the solution [28]. Figure 2 shows the smooth homogenous blend of tannin/PVOH (10/90) and coagulated particles in tannin/PVOH (25/75).

For simplifying the observations and discussions, we have divided the section into two parts. Part A discusses about the property variations of tannin PVAc blend by varying tannin concentration. For discussion in part $A$, we consider properties of PA 0/0.0, PA 1/0.0, PA 2/0.0, PA $4 / 0.0$ and $P A$ 6/0.0. PA 0/0.0 is a control sample. Part B deals with the effect on properties by adding isocyanate hardener to form an EPI blend. We considered all the samples mentioned in Table 2 for evaluation. PA 0/0.0, 
PA 0/2.5, PA 0/5.0 series is considered being a control sample series.

\subsection{Part A}

\subsubsection{Formulation}

Addition of tannin in the synthesises PVAc emulsion gives a smooth blend product. After adding 6 pph (on dry basis) of tannin, small particles were observed. These particles were similar to the coagulations we found in tannin/ PVOH blend. This observation is attributed to the formation of hydrogen bonding between tannin and polyvinyl alcohol present as a collide in PVAc emulsion.

\subsubsection{Dynamic mechanical analysis (DMA)}

Referring to Fig. 3, we observed that $T_{\mathrm{g}}$ increases with increase in tannin concentration. $T_{\mathrm{g}}$ increases from $40.70^{\circ} \mathrm{C}$ for the control sample PA $0 / 0.0$ to $42.78^{\circ} \mathrm{C}$ for PA 4/0.0. The sharp rise in $T_{\mathrm{g}}$ was observed between PA 0/0.0 and PA 2/0.0. Increase in $T_{g}$ is attributed to the formation of secondary hydrogen bonding of tannin with the hydroxyl of PVOH and carbonyl group. Secondary interactions also improve the elasticity (storage modulus) of the blend. Decrease in tan delta peak (Fig. 3) indicates the improvement in the elastic properties of the blend.

\subsubsection{Goniometry}

Measurement of contact angle provides essential information on surface wetting property of tannin PVAc emulsion adhesive. We observed a decrease in contact angle with an increase in tannin concentration in the blend. For control sample PA 0/0.0, value of surface contact angle is 44.02 $\theta(S D=0.62)$, whereas for PA 6/0.0, contact angle value is $40.01 \theta(S D=0.52)$. Figure 4 shows the trend of contact angle obtained by goniometry, and Fig. 5 shows the shape of water droplet while measuring the contact angle. The improvement in surface wetting property of the adhesive provides better penetration of adhesive in the wood substrate, which improves bonding strength $[29,30]$.

\subsubsection{Bonding strength}

From Fig. 6 and Table 5, we observe that D1 bonding strength values slightly increase from $9.61 \mathrm{~N} / \mathrm{mm}^{2}$ $(\mathrm{SD}=0.52)$ control sample PA $0 / 0.0$ to $10.24 \mathrm{~N} / \mathrm{mm}^{2}$ $(S D=0.29)$ for PA 4/0.0. However, the increase in $D 2$ bonding strength values is significant. D2 bond strength values for a control sample of tannin PA 0/0.0 were $5.20 \mathrm{~N} / \mathrm{mm}^{2}$ (SD 0.41) which increases to $8.09 \mathrm{~N} / \mathrm{mm}^{2}(\mathrm{SD}=0.40$ ) for PA $4 / 0.0$. The observed trend could be due to the presence of tannin, which makes adhesive more polar, which facilitates better wetting of wood surfaces and better penetration of adhesive in wood. The observation can be supported by goniometry results which indicate a decrease in water contact angle on increasing tannin content in tannin PVAc emulsion adhesive. Also, the presence of tannin provides strong hydrogen bonding which makes an adhesive compact and less susceptible towards the water. We observe PA 4/0.0, and PA 6/0.0 qualifies D2 bonding strength criterion as per EN 204. The heat resistance improves slightly with an increase in tannin content. Bond strength values for heat resistance test are $2.99 \mathrm{~N} / \mathrm{mm}^{2}(\mathrm{SD}=0.32)$ for $\mathrm{PA}$ 6/0.0 from $2.10 \mathrm{~N} / \mathrm{mm}^{2}$ (SD = 0.41) for PA 0/0.0. Improvement in heat resistance can be attributed to secondary bonding between the tannin hydroxyl group and the
Fig. 3 DMA curves indicating tan delta peak for PA 0/0.0, PA 2/0.0 and PA 4/0.0

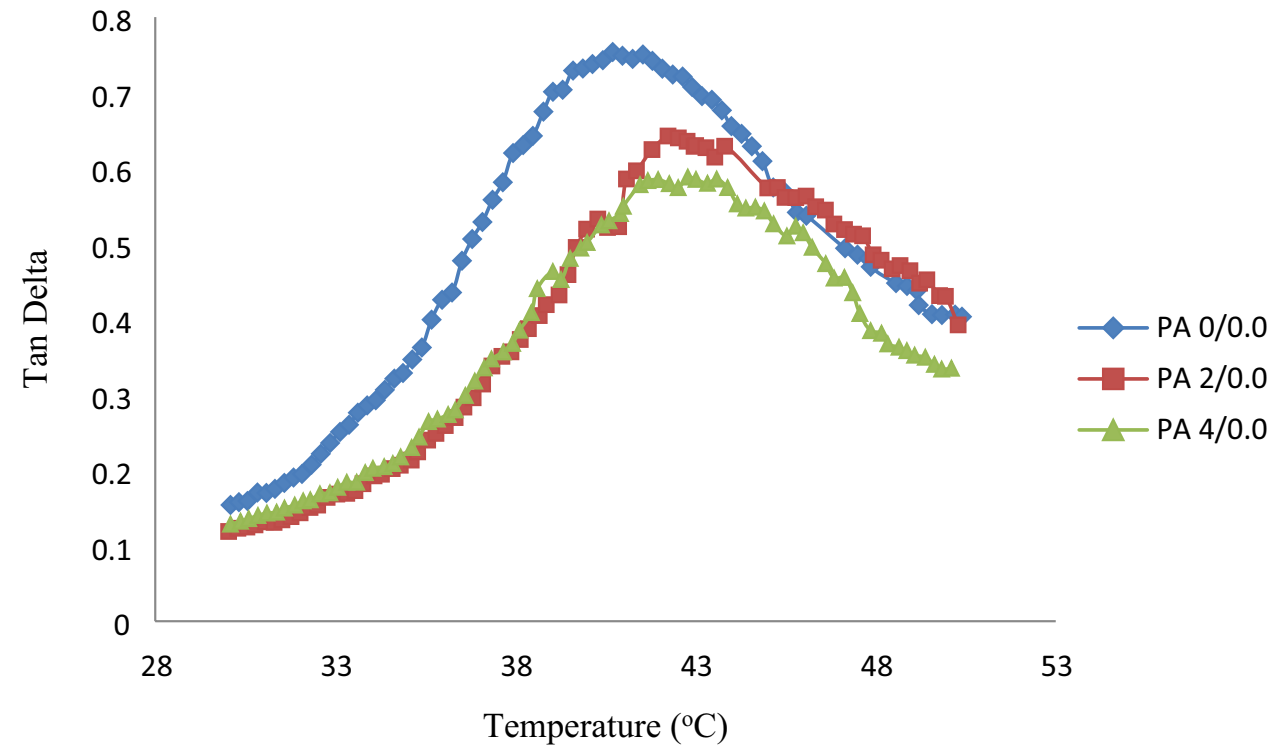


Fig. 4 Contact angle values for a different level of tannin in tannin PVAc emulsion adhesive

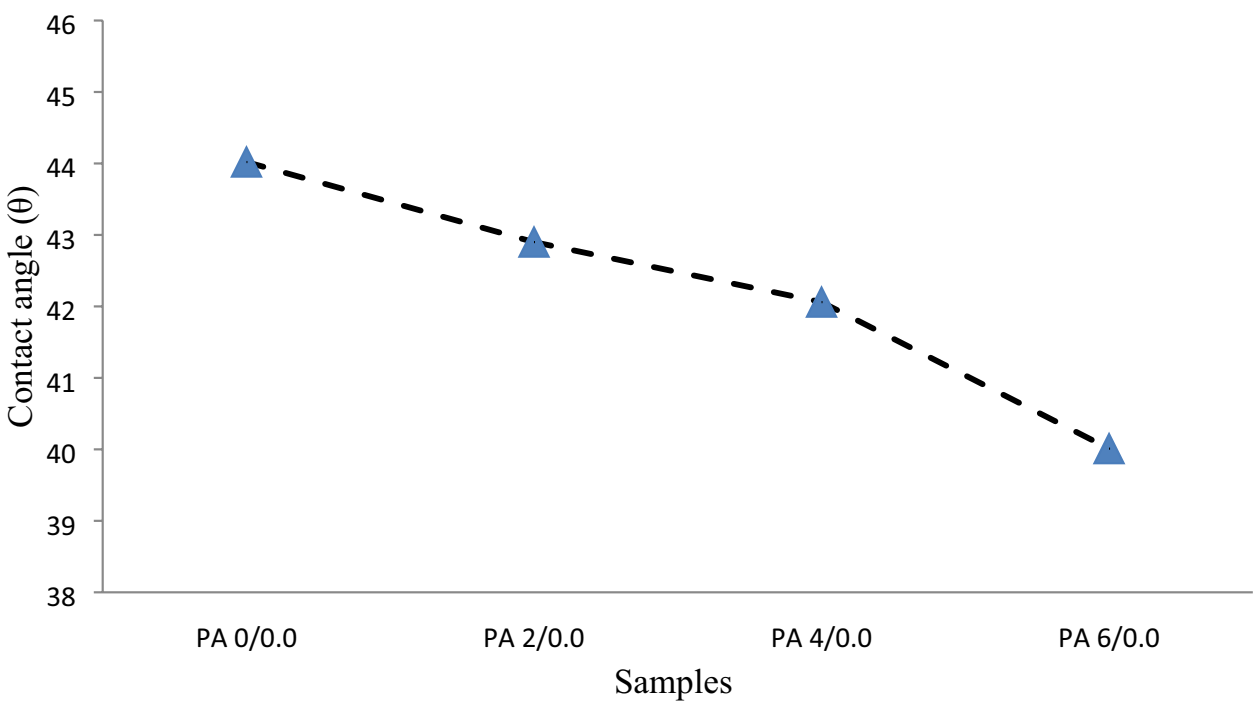

Fig. 5 Image of a water droplet on tannin PVAc emulsion adhesive film while measuring a contact angle on a goniometer
Fig. 6 Trend of adhesive strength measure for the specimen conditioned as per D1 and D2 of EN 204
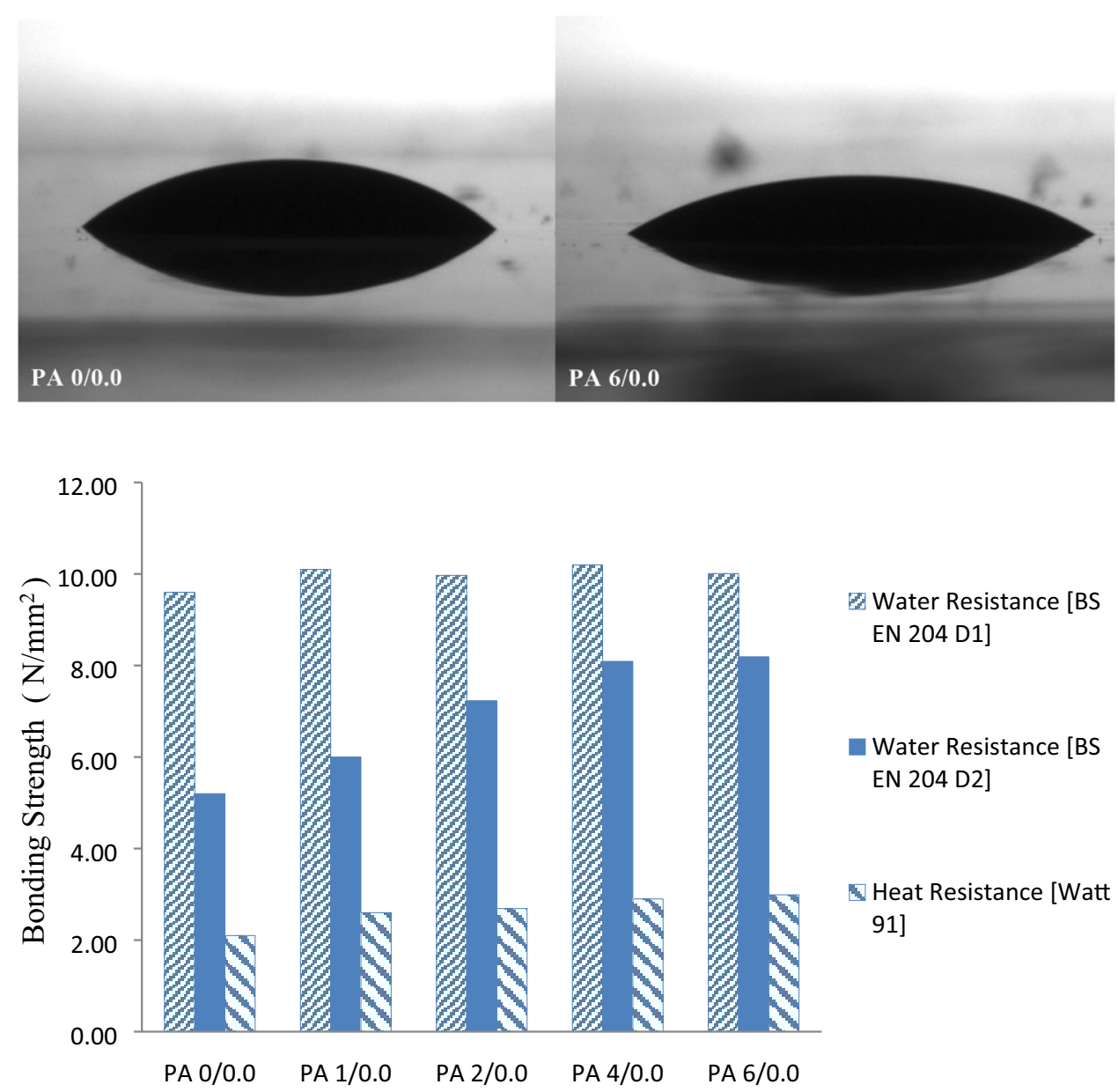

carbonyl group of PVAc [31] and between the hydroxyl group of $\mathrm{PVOH}$ and a tannin hydroxyl group.

\subsection{Part B}

\subsubsection{Viscosity}

From Fig. 7, we observed that the control sample PA 
Fig. 7 Viscosity variation over time on adding $5 \mathrm{pph}$ crosslinker in 0\% tannin PVAC emulsion adhesive (PA 0/5.0) and $4 \%$ tannin PVAc emulsion adhesive (PA 4/5.0)

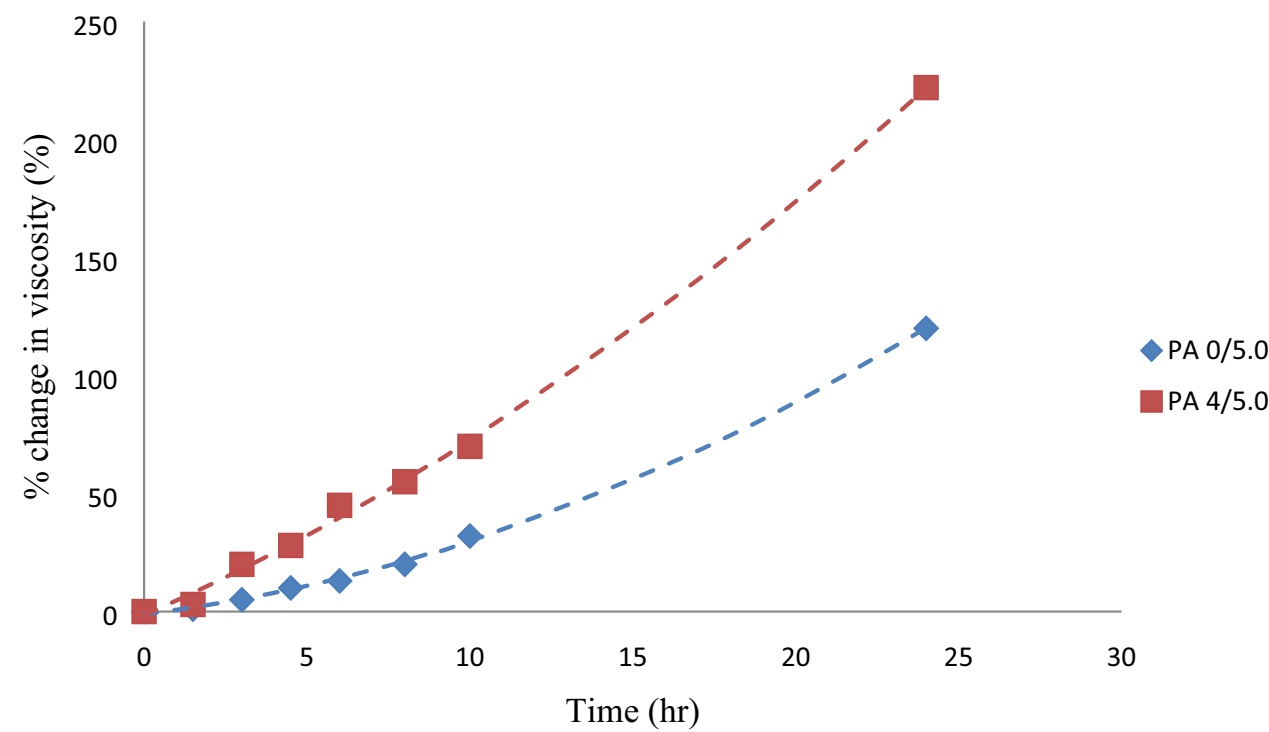

$0 / 5.0$ shows rise of $120 \%$ from its initial viscosity in $24 \mathrm{~h}$, whereas the viscosity of PA 4/5.0 shows an increase of $222 \%$ from its initial value in the same time. The rate of rising in viscosity for PA 4/5.0 is higher than PA 0/5.0. The observed phenomenon is attributed to the faster reaction of isocyanate with the phenolic hydroxyl group of tannin to form a denser crosslinked structure. The crosslinking facilitates the increment in viscosity of the adhesive blend.

\subsubsection{Fourier transform infrared spectroscopy (FTIR)}

From Fig. 8a, we observe, in tannin spectrum, a broad peak resembling hydroxyl groups in the region of 3000 and $3400 \mathrm{~cm}^{-1}$. On reacting tannin with a crosslinker, the intensity of hydroxyl peak is reduced, indicating that the hydroxyl group of tannin reacted with the isocyanate group of crosslinker. From Fig. 8b, complete reaction of the isocyanate group was confirmed by the disappearance of isocyanate (NCO) peak at $2255 \mathrm{~cm}^{1}$.
Fig. 8 FTIR spectrum overlay of tannin, tannin mixed with a crosslinker [tannin/crosslinker $(6: 1, w / w)]$ and a crosslinker. A indicates hydroxyl region and $B$ indicates isocyanate peak at $2244 \mathrm{~cm}^{-1}$

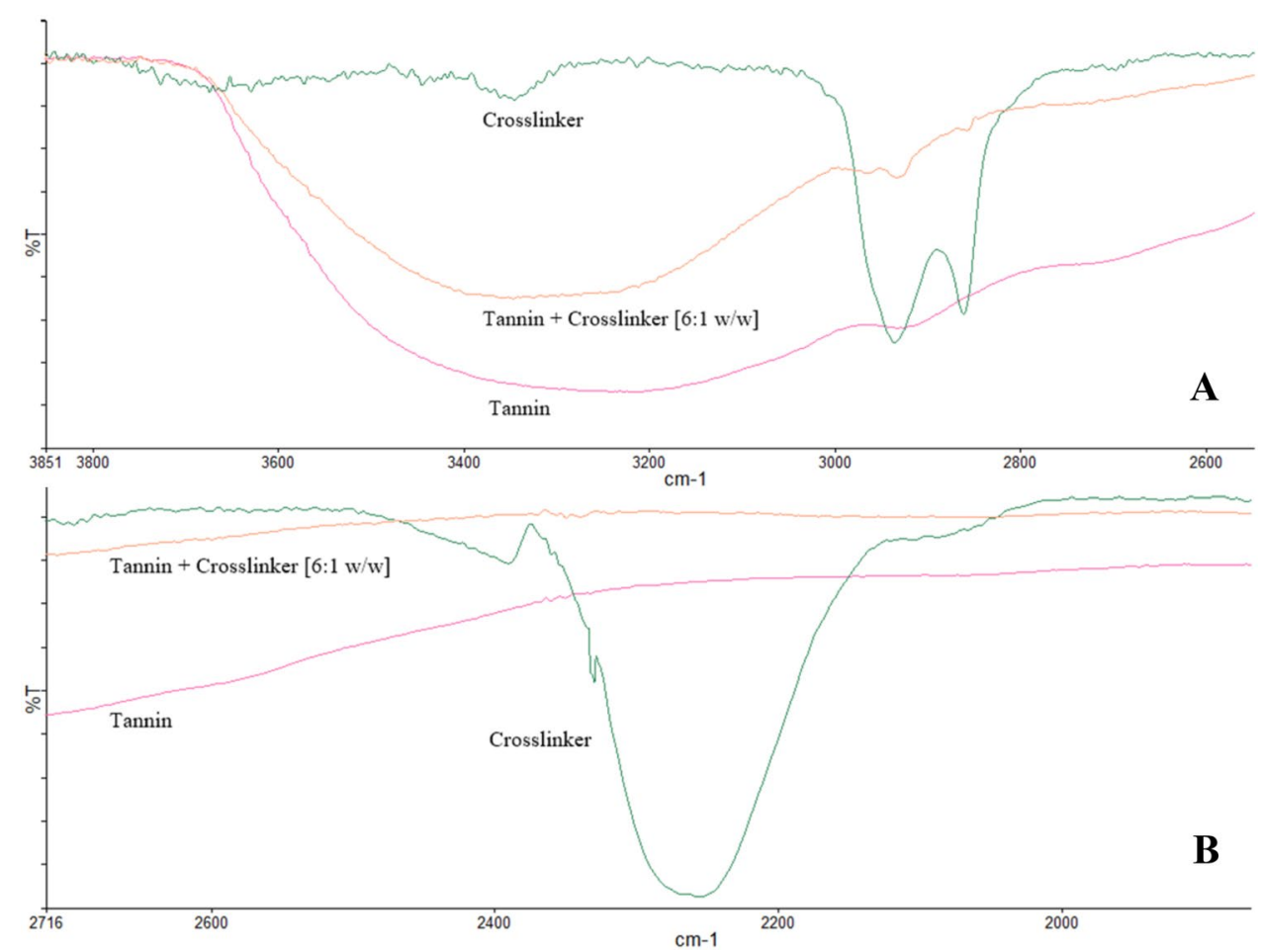


Table 4 Glass transition $\left(T_{\mathrm{g}}\right)$ values for tannin PVAc EPI measured using tan delta peak values obtained from DMA

\begin{tabular}{llll}
\hline $\begin{array}{l}\text { Glass transition temperature } \\
\left(T_{\mathrm{g}}\right)\left({ }^{\circ} \mathrm{C}\right)\end{array}$ \\
\hline Series & $\begin{array}{l}\text { Crosslinker concentra- } \\
\text { tion (pph) }\end{array}$ \\
\cline { 2 - 4 } & 0.0 & 2.5 & 5.0 \\
\hline PA 0 & 40.70 & 41.95 & 42.90 \\
PA 2 & 42.23 & 43.53 & 44.07 \\
PA 4 & 42.78 & 45.14 & 46.18 \\
\hline
\end{tabular}

\subsubsection{Dynamic mechanical analysis (DMA)}

Table 4 shows the variation of $T_{\mathrm{g}}$ on adding crosslinker in tannin PVAc emulsion adhesive system. We observed that the $T_{\mathrm{g}}$ increases on the addition of crosslinker. For control sample series of PA 0 , improvement in $T_{\mathrm{g}}$ is from $40.70^{\circ} \mathrm{C}$ for PA $0 / 0.0$ to $42.90^{\circ} \mathrm{C}$, for PA 0/5.0, i.e. the difference in $T_{\mathrm{g}}$ is $2.2^{\circ} \mathrm{C}$, whereas, for PA 4 series, with the addition of crosslinkers, $T_{\mathrm{g}}$ improves from $40.70^{\circ} \mathrm{C}$ for PA $4 / 0.0$ to $46.18^{\circ} \mathrm{C}$ for PA $4 / 5.0$, i.e. increment of $3.4^{\circ} \mathrm{C}$ in $T_{g}$ value. The observed improvement is attributed to better crosslinking in tannin PVAc emulsion adhesive system. This difference in $T_{\mathrm{g}}$ is small to compare. However, it indicates the increment in crosslinking in tannin PVAc EPI blend.

\subsubsection{Bonding strength}

The bonding strength of PVAc tannin EPI blend was assessed on the substrates conditioned as per EN 204 for water resistance and WATT 91 for heat resistance. From Fig. 9 and Table 5, we observed, for control series of PA 0, D2 bonding strength increase from $5.20 \mathrm{~N} / \mathrm{mm}^{2}$
$(\mathrm{SD}=0.41)$ for $\mathrm{PA} 0 / 0.0$ to $8.09 \mathrm{~N} / \mathrm{mm}^{2}(\mathrm{SD}=0.56)$ for PA 0/5.0. Incorporation of tannin in PVAc emulsion further improves the D2 bonding strength. For PA 4 and PA 6 series, as observed in part A, D2 bonding strength is $8.09 \mathrm{~N} / \mathrm{mm}^{2}(\mathrm{SD}=0.40)$ and $8.19 \mathrm{~N} / \mathrm{mm}^{2}(\mathrm{SD}=0.52)$, respectively. Addition of crosslinker into the blend further improves $D 2$ bonding strength to $10.20 \mathrm{~N} / \mathrm{mm}^{2}$ $(\mathrm{SD}=0.39)$ and $10.82 \mathrm{~N} / \mathrm{mm}^{2}(\mathrm{SD}=0.71)$ for PA $4 / 5.0$ and PA 6/5.0, respectively. From Fig. 10 and Table 5, we observed variation in D3 bonding strength values. For the samples without crosslinker, we could not measure the bonding strength values. Samples were too weak to handle the stress developed while testing the samples. Bonding strength improved on adding crosslinker. For PA0/5.0, we observed D3 bonding strength of $1.52 \mathrm{~N} /$ $\mathrm{mm}^{2}(\mathrm{SD}=0.41$ ), whereas for PA 4/5.0 and PA 6/5.0 D3 bonding strength was measured $2.12 \mathrm{~N} / \mathrm{mm}^{2}(\mathrm{SD}=0.27)$ and $2.01 \mathrm{~N} / \mathrm{mm}^{2}(\mathrm{SD}=0.19)$, respectively. We summarise that the prepared sample of PVA emulsion qualifies D1 criterion. Addition of minimum 4 pph tannin on a dry weight basis of emulsion qualifies the same emulsion to $D 2$ criterion. Addition of crosslinker further improves the bonding properties, which converts the adhesive to qualify D3 criterion. From Table 5, We observed the balance between tannin content and a crosslinker. Samples PA $1 / 2.5$ and PA $2 / 2.5$ qualify D2 criterion. If we expect to convert the synthesised adhesive for passing $D 2$ bonding strength, three options could be utilised. One is adding 4\% tannin in the PVAc emulsion (PA 4/0.0) and second is adding either 1 or $2 \%$ of tannin followed by addition of 2.5 pph of crosslinker (PA 1/2.5, PA 2/2.5). The third option is adding $5 \mathrm{pph}$ of crosslinker in the prepared PVAc emulsion(PA 0/5.0). The observation
Fig. 9 Bonding strength variation as per the D2 specification of BS EN204

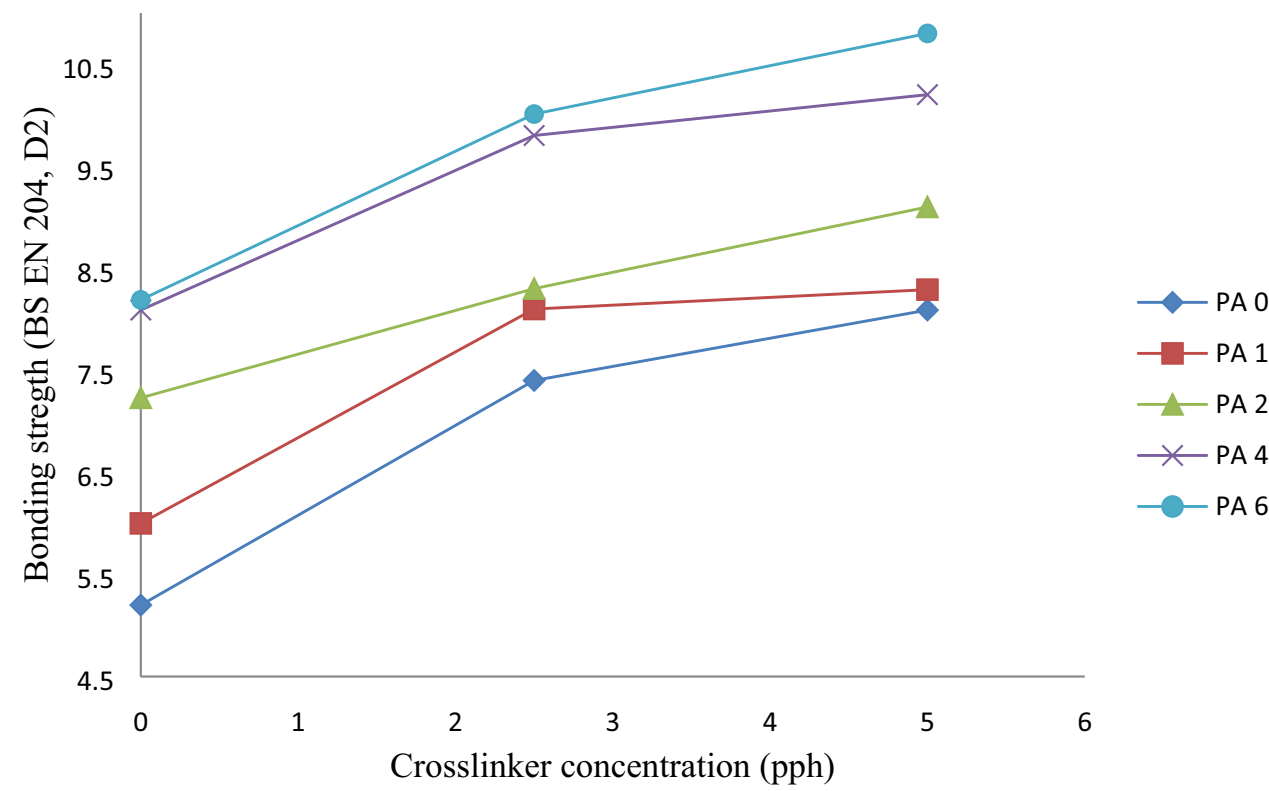

SN Applied Sciences A SPRINGER NATURE journa 
Table 5 Detailed bonding strength values for the samples under consideration

\begin{tabular}{lclllll}
\hline Samples & \multicolumn{2}{l}{ Bonding strength $\left(\mathrm{N} / \mathrm{mm}^{2}\right)$} & & \\
\cline { 2 - 7 } & D2 & SD & D3 & SD & Heat resistance & SD \\
\hline PA 0/0.0 & 5.20 & 0.41 & 0.00 & - & 2.10 & 0.41 \\
PA 0/2.5 & 7.40 & 0.52 & 1.06 & 0.26 & 2.30 & 0.28 \\
PA 0/5.0 & 8.09 & 0.56 & 1.52 & 0.41 & 2.83 & 0.35 \\
PA 1/0.0 & 6.00 & 0.23 & 0.00 & - & 2.60 & 0.36 \\
PA 1/2.5 & 8.10 & 0.63 & 1.42 & 0.59 & 3.14 & 0.54 \\
PA 1/5.0 & 8.29 & 0.31 & 1.79 & 0.53 & 3.22 & 0.25 \\
PA 2/0.0 & 7.23 & 0.44 & 0.00 & - & 2.69 & 0.38 \\
PA 2/2.5 & 8.30 & 0.39 & 1.60 & 0.31 & 3.12 & 0.29 \\
PA 2/5.0 & 9.10 & 0.26 & 1.82 & 0.49 & 3.53 & 0.31 \\
PA 4/0.0 & 8.09 & 0.40 & 0.00 & - & 2.91 & 0.21 \\
PA 4/2.5 & 9.80 & 0.29 & 1.59 & 0.75 & 3.41 & 0.52 \\
PA 4/5.0 & 10.20 & 0.39 & 2.12 & 0.27 & 3.79 & 0.40 \\
PA 6/0.0 & 8.19 & 0.52 & 0.00 & - & 2.99 & 0.32 \\
PA 6/2.5 & 10.01 & 0.49 & 1.64 & 0.33 & 3.55 & 0.18 \\
PA 6/5.0 & 10.82 & 0.71 & 2.01 & 0.19 & 3.72 & 0.29 \\
\hline
\end{tabular}

$\mathrm{SD}=$ Standard deviation

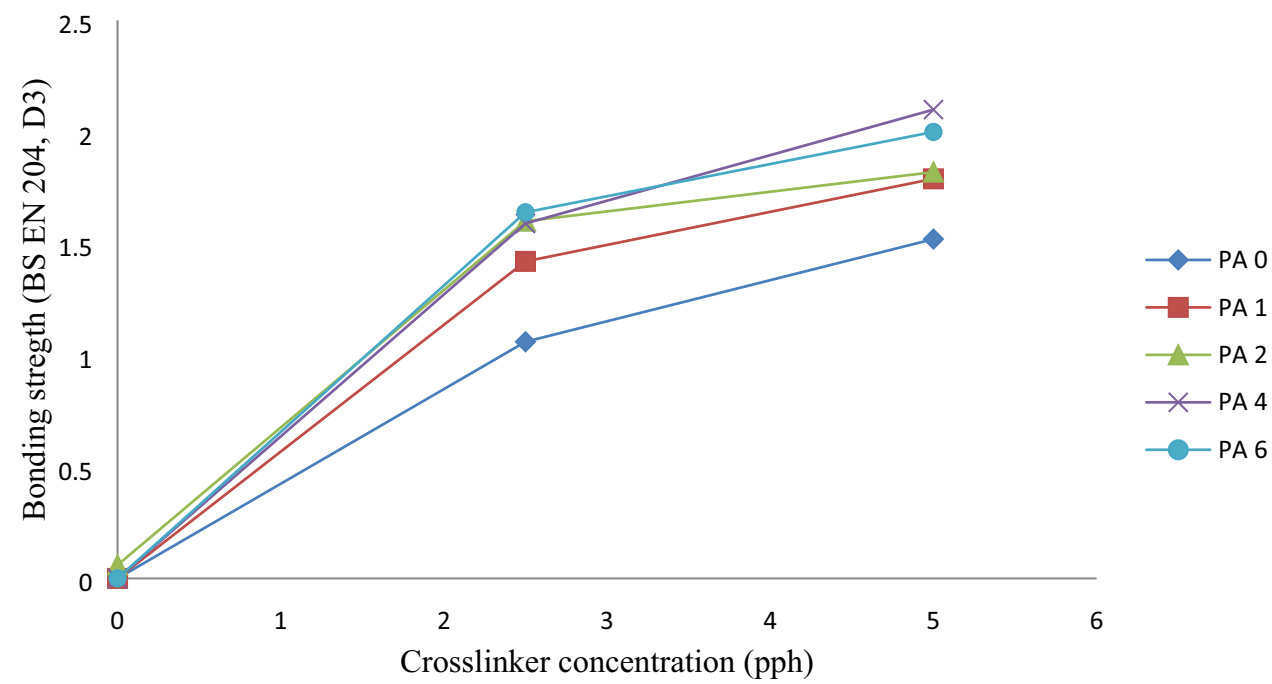

Fig. 10 Bonding strength variation as per $\mathrm{D} 3$ specification of BS EN204 indicates that the addition of tannin decreases the amount of crosslinker required in the system.

From Fig. 11 and Table 5, we observed variation in bonding strength test for assessing heat resistance property of the blend. For PA 0 series, bonding strength improves from $2.10 \mathrm{~N} / \mathrm{mm}^{2}$ ( $S D=0.41$ ) for PA0/0.0 to $2.83 \mathrm{~N} / \mathrm{mm}^{2}$ (SD = 0.35) for PA 0/5.0, whereas for PA 4 ad $\mathrm{PA} 6$ series, heat resistance bonding strength was $2.91 \mathrm{~N} /$ $\mathrm{mm}^{2}(\mathrm{SD}=0.21)$ for PA $4 / 0.0$ and $2.99 \mathrm{~N} / \mathrm{mm}^{2}(\mathrm{SD}=0.32)$ for PA 6/0.0 which increases to $3.79 \mathrm{~N} / \mathrm{mm}^{2}$ (SD $=0.40$ ) and $3.72 \mathrm{~N} / \mathrm{mm}^{2}(\mathrm{SD}=0.29)$ for PA 4/5.0 and PA 6/5.0, respectively. We observe that PA 4/5.0 and PA 6/5.0 qualify D3 criterion.

\section{SN Applied Sciences}

The overall improvement in bonding strength is attributed to the following observations which include better wetting property due to the presence of tannin measured by goniometry (Fig. 4), hydrogen bonding and dense crosslinking provided by crosslinking of multi-hydroxyl tannin, $\mathrm{PVOH}$ and isocyanate group. 
Fig. 11 Bonding strength variation as per Watt 91 specification

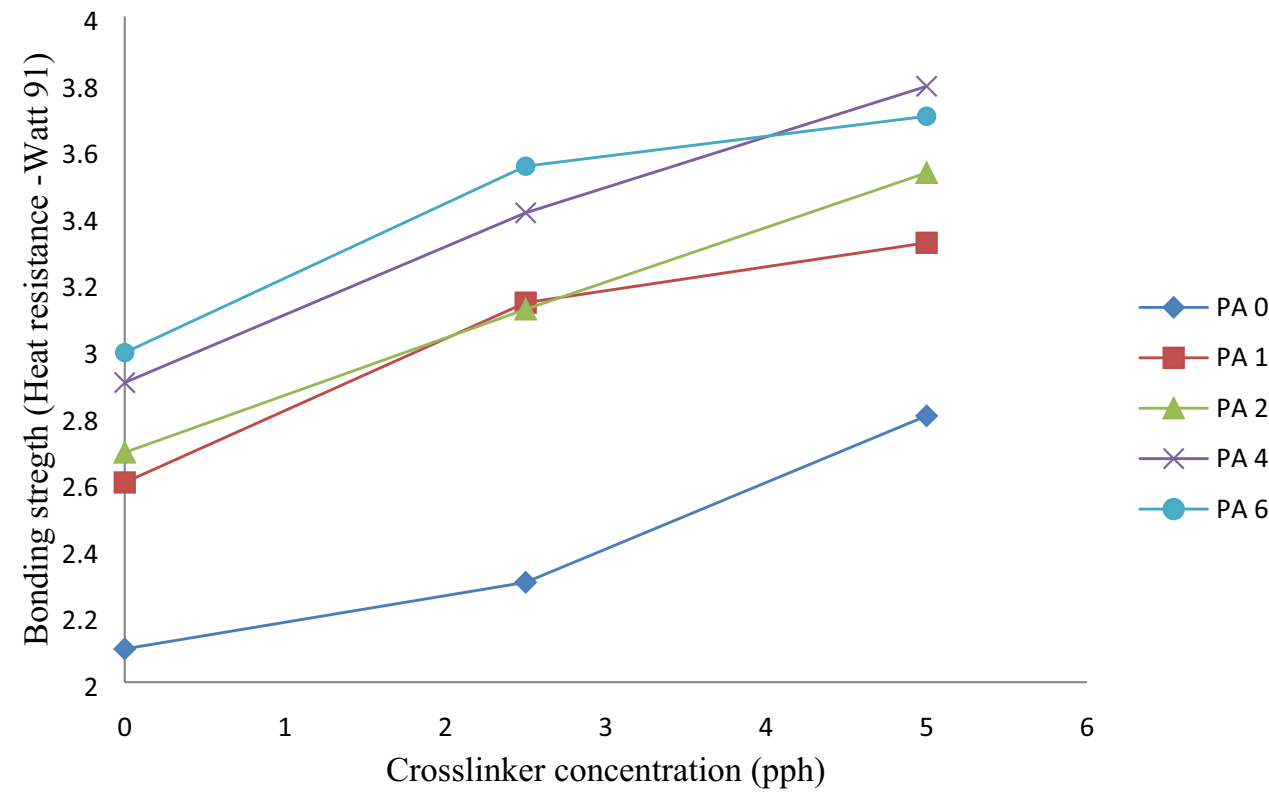

\section{Conclusion}

Wattle tannin extract helps in improving the water resistance and heat resistance property of polyvinyl acetate emulsion adhesive. From our research understanding, we can conclude

1. Tannin enhances the wettability of PVAc emulsion adhesive, which is observed from contact angle measurement using a goniometer.

2. Surface wetting property improves bonding strength, water resistance and heat resistance property.

3. Incorporating tannin converts a BS EN 204 D1 compliance adhesive to BS EN 204 D2 compliance adhesive.

4. By incorporating crosslinker, the viscosity of the system rises quickly due to faster reaction of the crosslinker with tannin.

5. Water resistance and heat resistance further improve in the presence of tannin and crosslinker converting a BS EN 204 D1 compliance PVAc adhesive to BS EN 204 D3 compliance adhesive.

The methods mentioned in the research provides a simple and cost-effective way to improve the PVAc adhesive performance by incorporating tannin in PVAc emulsion adhesive.

\section{Compliance with ethical standards}

Conflict of interest The authors declare that they have no conflict of interest.

\section{References}

1. Khanbabaee K, van Ree T (2001) Tannins: classification and definition. Nat Prod Rep 18(6):641-649

2. Rhazi N, Oumam M, Sesbou A, Hannache H, Charrier-El Bouhtoury $F$ (2017) Physico-mechanical properties of plywood bonded with ecological adhesives from Acacia mollissima tannins and lignosulfonates. Eur Phys J Appl Phys 78(3):34813

3. Sowunmi S, Ebewele RO, Conner AH, River BH (1996) Fortified mangrove tannin-based plywood adhesive. J Appl Polym Sci 62(3):577-584

4. El-Din HMF, El-Messery TM, Mehanna NS (2015) Interaction between some plants tannins and milk protein. Int J Food Nutr Sci 4(1):16-20

5. Deshpande SS, Cheryan M, Salunkhe DK, Luh BS (1986) Tannin analysis of food products. Crit Rev Food Sci Nutr 24(4):401-449

6. Tondi G (2017) Tannin-based copolymer resins: synthesis and characterisation by solid state 13C NMR and FT-IR spectroscopy. Polymers 9(6):223

7. Ghahri S, Pizzi A, Mohebby B, Mirshokraie A, Mansouri HR (2018) Soy-based, tannin-modified plywood adhesives. J Adhes 94(3):218-237

8. Navarrete P, Pizzi A, Bertaud F, Rigolet S (2011) Condensed tannin reactivity inhibition by internal rearrangements: detection by CP-MAS 13C NMR. Maderas Cienc Tecnol 13(1):59-68

9. Celzard A, Szczurek A, Jana P, Fierro V, Basso MC, Bourbigot S, Pizzi A (2015) Latest progresses in the preparation of tanninbased cellular solids. J Cell Plast 51(1):89-102

10. Pizzi A (1982) Pine tannin adhesives for particleboard. Holz als Roh-und Werkst 40(8):293-301

11. Ugovsek A, Kariz M, Sernek M (2010). Bonding of beech wood with an adhesive mixture made of liquefied wood and phenolic resin. In: Proceedings of the "Hardwood Science and Technology" - the 4th conference on hardwood research and utilisation in Europe. Sopron, Hungary, pp 17-18

12. Kim S (2009) Environment-friendly adhesives for surface bonding of wood-based flooring using natural tannin to reduce formaldehyde and TVOC emissions. Biores Technol 100(2):744-748 
13. Elbadawi M, Osman Z, Paridah T, Nasroun T, Kantiner W (2015) Mechanical and physical properties of particleboards made from Ailanthus wood and UF resin fortified by Acacias tannins blend. J Mater Environ Sci 6(4):1016-1021

14. Kim S, Lee JH, Kim J (2012). Application of tannin as green adhesive for environment-friendly furniture materials. In: 10th International conference on healthy buildings 2012, pp 931-935

15. Fang Q, Cui HW, Du GB (2013) Preparation and characterisation of PVAC-NMA-MMT. J Thermoplast Compos Mater 26(10):1393-1406

16. Guo J, Hu H, Zhang K, He Y, Guo X (2018) Revealing the mechanical properties of emulsion polymer isocyanate film in humid environments. Polymers 10(6):652

17. Grøstad K, Pedersen A (2010) Emulsion polymer isocyanates as wood adhesive: a review. J Adhes Sci Technol 24(8-10):1357-1381

18. Adamopoulos $S$, Bastani A, Gascón-Garrido P, Militz H, Mai C (2012) Adhesive bonding of beech wood modified with a phenol formaldehyde compound. Eur J Wood Wood Prod 70(6):897-901

19. Khan U, May P, Porwal H, Nawaz K, Coleman JN (2013) Improved adhesive strength and toughness of polyvinyl acetate glue on addition of small quantities of graphene. ACS Appl Mater Interfaces 5(4):1423-1428

20. Brown NR, Frazier CE (2007) Cross-linking poly [(vinyl acetate)co-N-methylolacrylamide] latex adhesive performance part I: n-methylolacrylamide (NMA) distribution. Int J Adhes Adhes 27(7):547-553

21. Bufkin BG, McGrawe JR (1978) J Coat Technol 50(641):41-55

22. Hass P, Wittel FK, Mendoza M, Herrmann HJ, Niemz P (2012) Adhesive penetration in beech wood: experiments. Wood Sci Technol 46(1-3):243-256
23. Lu J, Easteal AJ, Edmonds NR (2011) Crosslinkable poly (vinyl acetate) emulsions for wood adhesive. Pigm Resin Technol 40(3):161-168

24. EN 204/2001: Classification of thermoplastic wood adhesives for non-structural applications

25. I wata R, Inagaki N (2006) Durable adhesives for large laminated timber. J Adhes Sci Technol 20(7):633-646

26. Menard KP (1999) Dynamic mechanical analysis: a practical introduction. CRC Press, Boca Raton

27. DIN EN 14257 (WATT 91): Determination of tensile strength of lap joints at elevated temperature

28. Chen YN, Peng L, Liu T, Wang Y, Shi S, Wang H (2016) Poly (vinyl alcohol)-tannic acid hydrogels with excellent mechanical properties and shape memory behaviors. ACS Appl Mater Interfaces 8(40):27199-27206

29. Moredo CC Jr, Sakuno T, Kawada T (1996) The improvement of bond strength properties and surface characteristics of resinous woods. J Adhes 59(1-4):183-195

30. Wolkenhauer A, Avramidis G, Hauswald E, Loose S, Viöl W, Militz $H$ (2009) Investigations on the drying behaviour of adhesives on plasma-treated wood materials. Wood Res 54:56-66

31. Huang MW, Kuo SW, Wu HD, Chang FC, Fang SY (2002) Miscibility and hydrogen bonding in blends of poly (vinyl acetate) with phenolic resin. Polymer 43(8):2479-2487

Publisher's Note Springer Nature remains neutral with regard to jurisdictional claims in published maps and institutional affiliations. 